\title{
Willem Frijhoff, Embodied Belief. Ten Essays on Religious Culture in Dutch History
}

Hilversum (P-B), Verloren, 2002, 300 p. (coll. « ReLiC-Studies in Dutch Religious History », $\mathrm{n}_{0} 1$ )

Jean Séguy

\section{OpenEdition}

\section{Journals}

Édition électronique

URL : http://journals.openedition.org/assr/2342

DOI : 10.4000/assr.2342

ISSN : $1777-5825$

Éditeur

Éditions de l'EHESS

Édition imprimée

Date de publication : 1 avril 2004

Pagination : 47-112

ISBN : 2-222-96746-5

ISSN : 0335-5985

Référence électronique

Jean Séguy, "Willem Frijhoff, Embodied Belief. Ten Essays on Religious Culture in Dutch History », Archives de sciences sociales des religions [En ligne], 126 | avril - juin 2004, document 126.49, mis en ligne le 17 novembre 2005, consulté le 24 septembre 2020. URL : http://journals.openedition.org/assr/ 2342 ; DOI : https://doi.org/10.4000/assr.2342 
regard anthropologique et politologique, regrettée d'ailleurs dans le texte de conclusion, est parfois sensible. À l'exception d'un essai de typologisation en début d'ouvrage, c'est une succession de monographies, centrées sur les situations dans différents pays et construites le plus souvent suivant un cheminement chronologique, qui est proposée.

Les relations entre les Églises et les États sont abordées principalement sous un angle institutionnel, parfois même très juridique. Les croyants et les citoyens sont alors absents de nombreuses études focalisées sur les seuls liens entre des institutions et des leaders religieux ou des structures et des autorités étatiques.

Des expériences, en particulier africaines, privilégiées dans l'ouvrage, et asiatiques, semble transparaître, au-delà des spécificités nationales, liées au poids numérique variable des Églises chrétiennes dans ces différentes sociétés, un schéma historique identique : à une période de crispation, de tension et de répression des Églises dans les années soixante et soixante-dix succède, à partir des années quatre-vingt, une phase de libéralisation plus propice aux acteurs religieux. Ils l'utilisent à la fois pour développer leurs activités cultuelles, mais aussi pour investir la sphère publique. Cet engagement politique des Églises, plus spécifiquement en Afrique et dans le monde catholique, est présenté dans une perspective particulièrement bienveillante. Or, ces mobilisations en faveur de la démocratie, sont souvent le fait d'acteurs individuels et ne sont pourtant pas exemptes d'ambiguïtés et d'opportunisme.

En fournissant des études précises et détaillées, offrant certains éléments d'analyse pertinents, cet ouvrage peut s'avérer utile à l'élaboration d'une réflexion comparative et théorique sur les relations entre les Églises et les États, malgré le biais institutionnel présent dans plusieurs articles et l'absence d'études et de références anthropologiques et politologiques.

Cédric Mayrargue.

Guetter l'aurore. Un christianisme pour demain. Paris, Grasset, 2003, 284 p.

Précision et distinction capitales : voici un livre d'historien qui n'est pas un livre d'histoire. Dans la veine du Ce que je crois ou Ce que je pense, sur le mode du votif ou de l'optatif, ce livre de réflexion et de témoignages, sait mobiliser la culture historique de son auteur, sans se pencher, à l'aide de la méthode historique, sur le mouvement de la pensée chrétienne à laquelle il se réfère. Il s'agit d'un livre subjectif qu'on eût classé jadis dans les ouvrages d'apologétique pour offrir au chrétien moyen - voire au Français moyen une réfutation des objections faites au catéchisme de son enfance et lui proposer un horizon qui réponde à ses attentes. Un livre d'espérance, d'élagage, de conviction et de réconciliation, ouvert et généreux, comme il en existe déjà beaucoup sans qu'on puisse jamais dire trop. C'est une pièce nouvelle qui s'inscrit dans un débat en mal de s'ouvrir, mais non une étude de ce débat balbutiant et des déplacements qu'il opère.

Les théologiens le liront-ils ? A-t-il lu les théologiens ? Chacun œuvre dans son domaine, personne ne mesure le chemin parcouru depuis un siècle, ni les requêtes nouvellement apparues. Cette incertitude, ce flottement, cette hésitation de la pensée chrétienne, et plus encore son individualisation sont des données essentielles à prendre en compte. Michel de Certeau parlait d'un christianisme éclaté : ce qui apparaît au premier plan dans le catholicisme français, c'est bien l'éclatement de la pensée et l'incapacité d'en débattre ensemble.

Émile Poulat.

126.48

FRÉMONTIER (Jacques).

L'Étoile rouge de David. Les Juifs communistes en France. Paris, Fayard, 2002, 505 p. (index).

À partir de 100 interviews auprès de juifs, hommes et femmes, achkenazes et séfarades de tous âges, entrés et/ou sortis du Parti communiste, avant, pendant ou après la guerre, l'auteur restitue des parcours individuels et s'attache à montrer les sens divers donnés à l'engagement et à l'identité juive en donnant tour à tour la parole aux uns et aux autres. Un travail d'analyse, de mémoire, d'empathie et d'émotion.

Régine Azria.

126.49

FRIJHOFF (Willem).

Embodied Belief. Ten Essays on Religious Culture in Dutch History. Hilversum (P-B), Verloren, 2002, 300 p. (coll. « ReLiC-Studies in Dutch Religious History », $\mathrm{n}^{\mathrm{o}} 1$ ).

La religion - par les conflits qu'elle provoque et ses moments d'intolérance ou de tolérance - a toujours joué un rôle majeur dans la vie des Pays-Bas (ceux du Nord en particulier); jusqu'à ce que - après la fin de la 
Seconde Guerre mondiale - ce pays se transforme en une des sociétés les plus sécularisées de l'Europe occidentale. Son siècle d'or - le $\mathrm{XVII}^{\mathrm{e}}$ - fut éminemment religieux en même temps qu'assez tolérant pour que cela apparaisse même aux voyageurs (philosophes ou autres...) et que cela se sache de par le monde. C'est à ces temps d'utopie réalisée (mais l'utopie réalise-t-elle jamais pleinement ses potentialités ?) que notre collègue a consacré sa carrière et ses travaux. Aujourd'hui professeur d'histoire moderne à l'Université Libre d'Amsterdam, cet homme s'est fait une réputation suffisante - chez lui et hors de chez lui pour que ses collègues aient estimé conforme à l'ordre des choses de lui offrir, pour son soixantième anniversaire, le présent recueil de dix essais de sa plume - déjà ailleurs publiés - . Ceux-ci portent sur le domaine religieux dont l'auteur s'est fait une spécialité, dans la diversité qu'offre la palette de ses confessions et tendances au siècle d'or batave. Pour lui assurer un retentissement international plus certain, les responsables de cette initiative ont fait traduire en anglais ces articles, jusqu'ici disponibles en néerlandais uniquement.

Dans le choix qui a été fait en vue de ce recueil, ce sont les études abordant l'histoire religieuse comme phénomène de culture qui ont été privilégiées. Notre collègue a en effet joué un rôle de premier plan dans le passage - récent aux Pays-Bas - d'une Histoire de l'Église (ou des Églises) à une Histoire religieuse interconfessionnelle inspirée d'une «histoire des mentalités ».

W.F., qui collabore au Bulletin bibliographique des Archives depuis plusieurs décennies, a passé de nombreuses années à Paris, à l'ombre de l'EHESS et des Annales en particulier, du GSR et de notre revue aussi. On trouve trace de son compagnonnage avec les chercheurs de ces institutions et les œuvres qu'ils ont édifiées dans la dernière page du recueil (Épilogue), où l'A. s'explique sur le sens qu'il a voulu donner à son parcours d'historien.

Jean Séguy.

Close Harmony: A History of Southern Gospel. Chapel Hill-Londres, University of North Carolina Press, 2002, 394 p. (index, illustr.) (cf. supra, pp. 17-40).
GULAND (Olivier), ZERBIB (Michel).

Nous, Juifs de France. Entretiens. Entre communautarisme et laïcité, particularités et prises de positions d'une communauté qui s'affirme. 200 pages pour un état des lieux avec douze personnalités. Paris, Bayard éditions, 2000, 202 p. (glossaire), (coll. « Centurion»).

Les auteurs sont journalistes, tous deux dans des medias juifs. Le livre est né de la prise de conscience d'un changement de comportement des juifs de France depuis vingt ans, concomitant d'un changement dans les discours à leur égard de personnalités politiques de premier plan : progression de la pratique religieuse, et son corollaire, augmentation sensible de commerces casher, développement des radios juives, visibilité du CRIF, et dans le même temps donc, apparition du terme "communauté juive" dans le discours des trois derniers présidents de la République (ce qui ne s'était jamais produit auparavant, le "fait communautaire" apparaissant en contradiction avec l'idéal républicain).

Les AA. ont interrogé douze personnalités juives françaises sur le dialogue judéo-chrétien et judéo-musulman, sur les différentes sensibilités au sein du judaïsme cultuel, sur Vichy, les évolutions familiales (mariages mixtes, pacs, homosexualité), l'éducation, le Proche-Orient.

Et ce sont ces entretiens, riches d'enseignements pour le sociologue, avec le Grand Rabbin de France, les Présidents du Consistoire, du CRIF, de l'Alliance Israëlite Universelle, mais aussi avec des intellectuels comme Raphaël Draï, Marek Halter, Shmuel Trigano, Annette Wieworka ou avec le rabbin massorti Rivon Krygier, qui sont restitués ici.

Joëlle Allouche Benayoun.

126.52

HAMEL (Christopher de).

La Bible. Histoire du Livre. Paris, Phaidon, xi+352 p. (trad. de l'anglais par Nordine Haddad) (bibliogr., index, illustr.) (coll. « Arts décoratifs »)

L'ouvrage de C.D.H., docteur en paléographie, est un beau produit de la tradition anglo-saxonne de vulgarisation: clairement structuré, simple sans être simpliste, fourmillant d'anecdotes sans tomber dans l'anecdotique, il décrit avec élégance l'histoire de la Bible et est superbement illustré à l'aide de 237 photographies de très grande qualité. L'auteur se centre sur la destinée de la Bible en Occident et dans les terres qui ont fait l'objet de missions. Ce panorama s'ouvre donc sur 